\title{
Discussion on the Teaching Methods of Applied Undergraduate Computer Network Courses
}

\author{
Hui Chen ${ }^{1, a}$ \\ ${ }^{1}$ School of Computer Science and Technology Shandong Yingcai University, Jinan, 250104, China \\ aemail: chh2@163.com
}

Keywords: Teaching methods; Computer Network; Applied Undergraduate

\begin{abstract}
: the talents of applied undergraduate universities need to emphasize training students' professional application ability, but the traditional computer network courses teaching mode takes teachers as the main body, which makes the students lack the learning initiative and enthusiasm and can't get good teaching effect. The computer network teaching in the traditional teaching mode can't meet the social demand for network applied talents. So we should change the traditional teaching mode, apply inspiring interaction, case analysis, task-driven and various teaching methods comprehensively in the process of teaching around the aim of training applied talents, which will make the classroom teaching flexible and stimulate students' learning enthusiasm and initiative in order to achieve the training requirements of applied talents.
\end{abstract}

\section{Introduction}

Applied talents refer to the talents who are engaged in seeking direct interest for the society by using scientific principles. Their main task is to apply scientific principles or the new found knowledge directly to the field of social practice which is closely related to social production and living. With the further development of market economy, the production and business operation activities of the enterprises put forward new requirements for talents and the talents who have high professional quality and strong adaptability and get fast into the role meet with great favor of enterprises, which has brought new opportunities and challenges to the talent training of the applied undergraduate universities [1]. The talents trained by the applied undergraduate are just the advanced technical talents who adapt to the first line need of production, construction, management and service. On the training mode, the applied undergraduate takes adapting to the social need as the goal and training technology application ability as the main line to design the students' knowledge, ability, quality structure and cultivation schemes, who takes the "application" as the purpose and characteristic to construct courses and teaching content system and pays attention to the cultivation of students' technical application ability.

With the rapid development of computer network technology, the society demand for a high level of computer network application talents will continue to increase, and the professional and technical personnel who are proficient in computer network knowledge and network system planning, design, construction and maintenance with strong manipulative ability are favored particularly. The society demand for computer network application talents accordingly puts forward new challenges to the university computer network courses teaching.

\section{The Characteristics of Computer Network Courses}

Computer network is a compulsory professional basic and core course of computer professional students. With the arrival of cloud computing, Internet of things, and the Age of Big Data, computer network has become the core infrastructure of the emerging information technology. At the same time, it is closely related to information security, Web programming, and other technologies. Therefore, computer network courses become more and more important in the knowledge system of professional personnel training.

The main content of the computer network courses gives priority to mature network technology and systematically teaches the related concepts, principles and application technology to the students. Its purpose is to help students to master the computer network architecture and popular 
reference model, to master the basic principles and data communication technology of the physical layer standard, to master the working principle and common instances of data link layer protocol, to master the basic principle and organizing method of LAN, to master the basic principle and access method of WAN, to master the basic knowledge of network interconnection and the operation mechanism of IP protocol, to master the working principle of the transport layer and the operation principle of TCP/UDP protocol, and to master the common protocols of the application layer, the working principle of network services, and the architecture method of the application system. It also makes the students understand the frontier technology of the development of computer network technology, which lay a solid foundation for cultivating students' abilities in computer network system planning and construction and the establishment and development of network application system. But because computer network courses contain lots of theory knowledge points, concepts, definitions, and protocols and abstract content, the overall feeling of the students in the learning process is the content is abstract, empty, and difficult to understand, so their learning interest is often not high.

\section{To Adopt Reasonable Teaching Methods}

The traditional computer network courses teaching lays emphasis on theoretical knowledge learning. For the students of general undergraduate universities and colleges, a lot of daunting theoretical knowledge makes them complain constantly. Even if the students master a lot of theory, but their manipulative ability is still very poor in the actual work. In order to reflect the training requirements of applied talents at the same time of the basic theory teaching, we need to adopt reasonable teaching methods to correspond to the target of applied undergraduate talents training.

Guide and Interactive Teaching Approach. The guide and interactive teaching approach emphasizes taking the students as the subjects of teaching. And the teacher should mobilize the learning enthusiasm of the students, realize the teachers' leading role, and let the students actively participate in classroom teaching activities and carry on a heated discussion of the teaching content, in which the students master the teaching content. Teachers can set up hierarchical questions according to the teaching content and put forward the inquiry points from the shallower to the deeper explore to inspire the students to think actively and to train the students' ability to analyze and solve problems [2]. In this interactive way, we can mobilize the classroom atmosphere fully and effectively. Such as in the part of satellite communication in the computer network courses, we guide the students to find and understand about the characteristic that "the satellite channel transmission delay is larger" through the problem, "Why the dialogue between the anchor and the reporter is not smooth in the satellite link in the TV live broadcast?" In the classroom, through "What communication modes can you think of in the daily life?", we can get the circuit switching, message exchange and packet switching of the communication equipments, data transmission lines and data switching technology used in computer communication which contain the entire content of the network data communication technology. When some problems are first put forward, the state of the students is very puzzled. After simple guidance, the students will get into a groove and put forward all kinds of thoughts, some even are just ideas, and the classroom atmosphere will gradually get active. Then the teacher needs to timely guide the students from divergent thinking back to the summary thinking classify the idea to put forward from the brainstorming so as to grasp the teaching contents. In the process, we should pay attention to the students' aptitude and differential treatment. The teacher's explanation of the teaching material should be from easy to difficult to ensure that every student in the class can get something in the activities of teaching. The teacher should encourage the students to communicate with each other and to share the understanding and comments of the teaching content. This can both improve the relationship between the students and promote the improvement of the overall level of the students. In addition, the teacher can decorate problems and tasks of the teaching contents in the teaching and arrange students to use the web to consult relevant data and to deal with some problems of them through the network, which can both mobilize the enthusiasm of the students and cultivate the good habit of combining mind and hand. 
Case-teaching Method. The case-teaching method means that the teacher needs to use the actual cases which are closely related to the teaching content to solve various problems in the teaching according to the requirement of the curriculum teaching goal and content [3]. They should organize the students to study and discuss to improve the students' ability of thinking, analyzing and solving problems and to train the students' keen interest in learning. The practical demand of computer network curriculum is high, while the theoretical knowledge is abstract. The systematic theoretical knowledge can hardly stimulate students' interest in learning, which goes against carrying on teaching activities smoothly, thus we can appropriately carry out the case teaching in the classroom teaching. And we should stimulate the students' interest in learning through the cases and use cases activation theory knowledge to make the students have a more profound, specific, visual, and thorough understanding of theory knowledge. For example, in the course overview, the teacher illustrates the Internet is a field which make people feel both excited and nervous through a large number of specific cases, numbers, and charts, and then puts forward issues, such as, what is "Internet", " how does the design of the Internet deal with a variety of new challenges", to stimulate students' interest in understanding and studying the internal principles of the Internet. The ultimate goal of teaching is to let students to apply classroom knowledge in real life [4]. In some chapters, we add some instances related to daily work and life to make the students feel the practicability and intentionality of learning, so as to stimulate students' interest in learning. For example, taking the campus network of our university as a teaching case, it fully introduces the topology structure, main equipments, site configuration, daily maintenance, etc. of the campus network, which blends the theory knowledge in the textbook into the case to promote the students to understand the abstract theory knowledge more clearly. It also make the abstract theory knowledge be visualized, specific and popularized, and finally the students summarize the construction, maintenance, and management of the campus network and put forward constructive suggestions for the upgrading and rebuilding, maintenance and management of the campus network, which achieves the mastery through theoretical knowledge and practical knowledge. After the analysis of the campus network, we take some large enterprise websites which are familiar to the students as examples and let the student analyze the contents and realize the migration of knowledge. When using the case-teaching method, the selected cases should not be too difficult and the scale should not be too big, otherwise it will bring big burden to the students' understanding, thus affecting the teaching effect.

Task-driven Teaching Method. Task-driven teaching method advocates that the students occupy the center of teaching in the process of teaching, and the teacher is more of a guide to the students, which suggests letting the students to explore and study in practice independently [5]. In the classroom teaching, the task-driven method is to set corresponding teaching tasks according to the teaching content and to carry out teaching around the tasks, which possesses more specific teaching content and purpose than the traditional teaching methods. At the same time, the task-driven teaching method also stresses that the student constantly solve problems under the drive of the tasks in the real situation to complete the tasks and carry out constant learning activities. In the reform of computer network teaching methods, the teaching mode based on the task-driven is the combination of knowledge and experiment, and it designs the learning tasks including the knowledge points and validates and studies them in the process of experiment. For example, the teaching of network technology configuration involves the switch, route and network security and other knowledge points. Only a switch experiment is related to the basic switch configuration, virtual local area network (VLAN) and many other aspects. It has lots of contents and command, which the students can not accept at a time. In the process of teaching activities, we can take the network topological structure of campus network as a situational task, ask the students to configure related network equipments. The purpose is to make the dormitory computers of the students can have access to the Internet. Because the task is closely related to the students' Internet at ordinary times, they immediately become interested in it. The task-driven teaching method can make the students use the computer network principles and experimental skills to analyze and solve practical problems according to task requirements in different network engineering phases and form the final solution at the end of each phase. The students get familiar with the project process, deepen their 
own understanding of the entire structure of the network system, and strengthen their ability of network design, implementation, management and protocol analysis in the realization process of the demand.

\section{Conclusion}

Computer network is a course which contains both professional theoretical study and practical application with the characteristics of wide content, wide range and scattered knowledge points, etc. According to the teaching requirements of the applied undergraduate education, we should change the traditional teaching mode, surround the applied talents training goal, combine with the characteristics of computer network courses, use the multimedia teaching, and apply the inspiring and interactive teaching, case analysis, task-driven method and other teaching methods in the process of teaching. We should also make the classroom teaching flexible, stimulate students' learning enthusiasm and initiative, and focus on training the students' innovative spirit and practical ability in order to achieve the requirements of applied talents training.

\section{References}

[1] K.M. Gu: Research and Practice of the Training Mode of the Practical Talents Majored in Computer, edited by Liaoning Education Research, Vol. 10 (2007), p.84-86

[2] J.L. Zhang: Research and Discussion on Teaching of University Computer Network Course, edited by Journal of Yangtze University (Nat Sci Edit), Vol. 10(2013), p.99-100

[3] H.Chen: Research on Teaching method of Assembly Language in Applied-Oriented Colleges, edited by Computer Programming Skills \& Maintenance,Vol.24 (2011), p.157-158

[4] J.S.Yuan, J.D.Qi: Thinking of the Reform and Practice of Computer Network Curriculum Teaching, edited by Forestry Education in China, Vol. 31(2013), p.56-58

[5] T.Wen: Task-driven method Practice in computer network teaching, edited by China Computer \& Network, Vol. 9(2008), p.65-67 